\title{
SOME DYNAMICS STUDIES ON URUMQI GLACIER No. 1, TIANSHAN GLACIOLOGICAL STATION, CHINA
}

\author{
by
}

Huang Maohuan, Wang Zhongxiang, Cai Baolin, and Han Jiankang

(Lanzhou Institute of Glaciology and Geocryology, Academia Sinica, Lanzhou, China)

\section{ABSTRACT}

The zero isopleth of surface areal strain-rate is roughly parallel to, but below, the equilibrium line of the glacier. In the middle and lower parts of the ablation area, the basal temperature is either close to or at the melting point, whereas above and around the equilibrium line the glacier is frozen to its bed. The basal bulk ice is deforming continuously and inhomogeneously but, in the inner parts of the glacier, where the strain-rate is smaller, homogeneous deformation can only be assumed conditionally. In the ablation area, pure shear is predominant near the base of the glacier and simple shear becomes progressively more important from the inner parts of the glacier towards its margins.

\section{INTRODUCTION}

Urumqi Glacier No. 1 is an extra-continental type glacier, sometimes classified as a sub-polar glacier. It is located in the hinterland of Eurasia at $43^{\circ} 06^{\prime} \mathrm{N}, 87^{\circ} 15^{\prime} \mathrm{E}$. Its equilibrium line is at about $4050 \mathrm{~m}$ a.s.l., where the annual precipitation is about $550 \mathrm{~mm}$ water equivalent and the mean annual temperature is $-10^{\circ} \mathrm{C}$. It is a smal cirque-valley glacier, $2.2 \mathrm{~km}$ long, and is both retreating and thinning.

Glacier-flow measurements, which began in 1959, have shown that the velocity is decreasing, e.g. the velocity averaged for May 1980 to May 1981 had decreased by $31-73 \%$ compared with that for 1959-62 (Sun and others, 1985).

Some observations on glacier dynamics have been made since 1980 with the aim of investigating the flow mechanisms of continental-type glaciers. Echelmeyer and Wang (1987), Huang and Wang (1987), and Echelmeyer (1987) have described their observations which were made in a tunnel excavated close to the glacier bed at an elevation of $3820 \mathrm{~m}$. We should now like to present some new results for this glacier.

\section{SURFACE AREAL STRAIN-RATE}

Fifty-four points, where surface velocity was measured, were distributed over the glacier, which has an area of $1.84 \mathrm{~km}^{2}$. By using the processing method of Meier and others (1974), we can draw a map showing the distribution of surface strain-rate and the isopleths of surface areal strain-rate for the glacier. Figure 1 is one of these maps based on the survey data for the period 19 May 1980-18 May 1981. Data for the horizontal flow velocity were used and the vertical components were eliminated. The error in the strain-rate is generally estimated to be $\pm 0.25 \times 10^{-2} \mathrm{a}^{-1}$ but it is $\pm 0.5 \times 10^{-2} \mathrm{a}^{-1}$ at the margins. As shown in Figure 1, zero isopleths for surface areal strain-rate occur in both the eastern and western branches of the glacier; up-stream of these isopleths, the areal strain-rate is positive and down-stream it is negative, i.e. up-stream there is extending flow and down-stream there is a compressive-flow area.

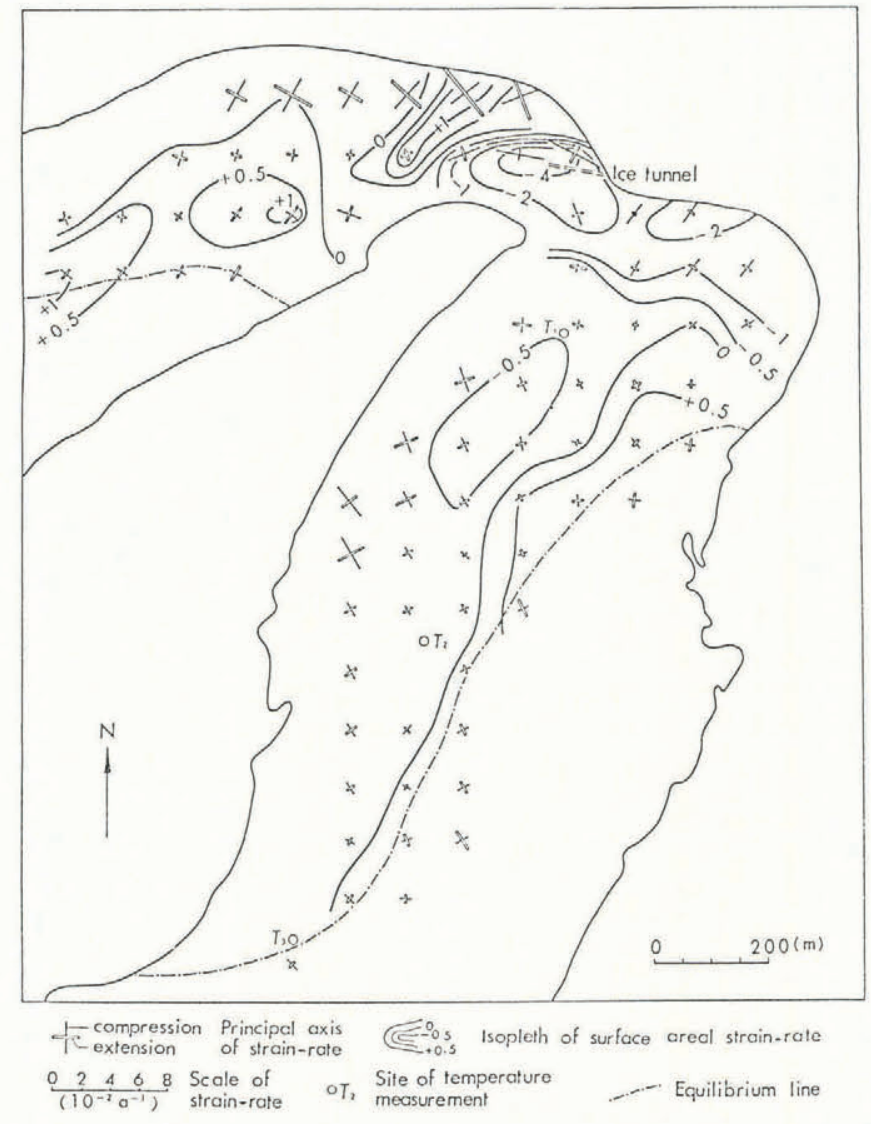

Fig. 1. A map showing the distribution of surface strain-rate and isopleths of surface areal strain-rate on Urumqi Glacier No. 1. An ice tunnel and three sites of temperature measurement are also shown.

However, these isopleths do not coincide with the equilibrium lines. They are roughly parallel to, but below, the equilibrium line. In the compressive-flow area, there are some local zones of extending flow, e.g. there is a positive areal strain-rate zone in the middle part of the western branch, at the top of a steep section of the glacier. The maximum areal strain-rate does not occur at the terminus but at the bottom of the steep section of the glacier. The maximum shear strain-rate occurs at the outside of a bend, particularly the bend in the western branch, where many crevasses have formed.

\section{ICE TEMPERATURE}

Ice temperatures in Urumqi Glacier No. 1 have been measured in detail; Huang and others (1982) have summarized measurements up to 1978. Since then, Ren and others (1985) have made more detailed measurements. In the 
ablation area, the ice temperature is quite low in the active layer but it increases rapidly downwards. Huang and others (1982) have pointed out that, in many small-scale glaciers, such as Urumqi Glacier No. 1, the temperature at the base of the active layer is generally higher than the mean annual air temperature at the same elevation, whereas the ice at the base of the glacier is usually at the melting point. By extrapolating from data obtained from depths of not more than $35 \mathrm{~m}$, Ren and others (1985) have concluded that the temperature at the base of the glacier is at the melting point at some places but not at others. Huang and Wang (1987) published the ice-temperature data measured in the tunnel (Fig. 1); these show that the ice temperature below the floor of the tunnel is close to but not at the melting point. In addition, in September 1983, they observed water springing up from a hole in the tunnel floor. In the period September-November 1984, Echelmeyer (1987) measured the ice temperature in a lateral shaft connected to the main ice tunnel. A basal temperature gradient of $0.3 \mathrm{~K} \mathrm{~m}^{-1}$, more than an order of magnitude greater than the geothermal gradient, was recorded in the shaft, where the ice thickness is about $22 \mathrm{~m}$. Echelmeyer believed that ground water flowing beneath the glacier is responsible for this large basal temperature gradient, and he calculated that there is a subglacial upward heat flow of $0.6 \mathrm{~W} \mathrm{~m}^{-2}$, which requires a water flux of about $0.1 \mathrm{~m}^{3} \mathrm{~s}^{-1}$ over the $400 \mathrm{~m}$ width of the glacier.

In July 1986, three holes were drilled with a hot-water drill in the lower and middle parts of the ablation area and near the equilibrium line in the eastern branch of the glacier, respectively, for the measurement of ice temperature (Cai and others, 1987). The sensors had an accuracy of $\pm 0.05 \mathrm{~K}$. The elevations at the tops of the holes were $3854 \mathrm{~m}$ for $\mathrm{T}_{1}, 3928 \mathrm{~m}$ for $\mathrm{T}_{2}$, and $4033 \mathrm{~m}$ for $\mathrm{T}_{3}$ (Fig. 1). The depths of the bore holes were 86,102 , and $106 \mathrm{~m}$, respectively. According to radar sounding, the maximum ice thickness is $140 \mathrm{~m}$ in the eastern branch of the glacier, and

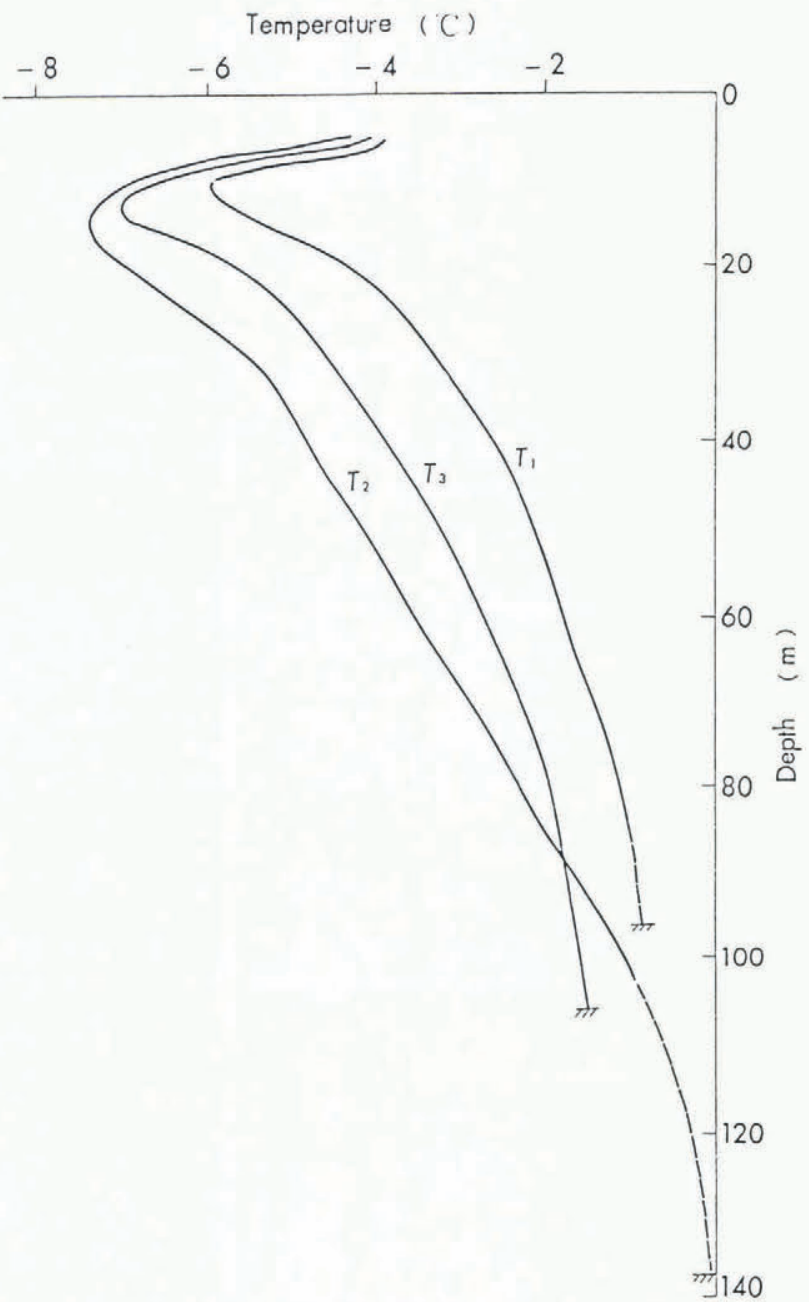

Fig. 2. Temperature profiles measured on 8 August 1986.

The dotted line is an extrapolation.
TABLE I. TEMPERATURES $(T)$ AND TEMPERATURE GRADIENTS $(\mathrm{d} T / \mathrm{d} z)$ FOR THE THREE SITES

Site

$T\left({ }^{\circ} \mathrm{C}\right)$

$$
\mathrm{T}_{1}
$$

$\mathrm{T}_{2}$

$\mathrm{T}_{3}$

At the bottom

$-4.8$

$-0.7$

$-6.6$

$-1.0$

$-5.6$

$\mathrm{d} T / \mathrm{dz} z\left(\mathrm{~K} \mathrm{~m}^{-1)} \begin{array}{l}\text { From } 20 \mathrm{~m} \text { depth } \\ \text { to the bottom } \\ \text { Lowest } 20 \mathrm{~m}\end{array}\right.$

0.044

0.066

0.029

0.050

at $T_{1}, T_{2}$, and $T_{3}$ the thicknesses are 96,138 , and $106 \mathrm{~m}$, respectively (Zhang and others, 1985). Therefore, bore hole $\mathrm{T}_{3}$ reached the base of the ice and $T_{1}$ was close to it. For $T_{1}, T_{2}$, and $T_{3}$, the net mass balances are $-1,-0.5$, and $0 \mathrm{~m} \mathrm{a}^{-1}$, respectively. The temperature profiles measured on 8 August 1986 are shown in Figure 2.

The temperatures at a depth of $20 \mathrm{~m}$ and at the bottom of bore holes at the three sites are listed in Table I. The temperature gradients from a depth of $20 \mathrm{~m}$ to the bottom of each bore hole and the gradients in the lowest $20 \mathrm{~m}$ of each bore hole are also shown.

From Figure 2 and Table $I$, we can see that the temperature gradients in the upper layer are greater than those in the lower layer. Apart from the ice flowing upward towards the surface, carrying warm basal ice with it, Cai and others (1987) have suggested that the up-stream temperature significantly affects the down-stream temperature by means of horizontal conduction and advection. Generally speaking, the mean temperature gradient from a depth of $20 \mathrm{~m}$ to the bore-hole bottom is two to three times greater than the geothermal gradient. But the mean temperature gradients of the lowest $20 \mathrm{~m}$ of the bore holes are less than this and agree with what Echelmeyer (1987, table 2) had calculated. For the prescribed temperature conditions at the surface $T=-10^{\circ} \mathrm{C}$, the net mass balance $b=-1$ to $-2 \mathrm{~m} \mathrm{a}^{-1}$, and glacier thickness $H=100 \mathrm{~m}$, he had calculated that $(\mathrm{d} T / \mathrm{d} z) /(\mathrm{d} T / \mathrm{d} z)_{\mathrm{e}}=1.1-2.2$, where $(\mathrm{d} T / \mathrm{d} z)_{\mathrm{e}}$ is the geothermal gradient $\left(=0.023 \mathrm{~K} \mathrm{~m}^{-1}\right)$. On the basis of the temperatures at the bottom of the bore holes and the temperature gradients in the lowest $20 \mathrm{~m}$ (Table I), we believe that in the middle and lower parts of the ablation area the temperature at the base of the glacier will be close to (e.g. at $\mathrm{T}_{1}$ ) or at (e.g. at $\mathrm{T}_{2}$ ) the melting point. But the temperature at the base of $\mathrm{T}_{3}$ is $-1.8^{\circ} \mathrm{C}$, which implies that above and around the equilibrium line the glacier is frozen to its bed.

\section{DEFORMATION OF ICE}

In the tunnel, there is clear bulk ice above the layer of ice-laden subglacial till and its deformation was observed regularly in both 1983 and 1984.

\section{Inhomogeneity}

Inhomogeneous deformation of the ice was observed from 18 January to 13 November 1984. Two circular peg arrays, $A_{r}$ and $A_{\ell}$, for observing deformation were fixed on the southern and northern walls at section $A$ in the tunnel, and five circular peg arrays, D-1, D-2, .., D-5, were fixed on the southern wall at section D of a lateral shaft connected with the tunnel. The locations of the arrays are listed in Table II. Each array comprised 17 pegs frozen into the ice. Among them, one is the origin (0), eight $\left(I_{1}\right.$, $\mathrm{I}_{2}, \ldots, \mathrm{I}_{8}$ ) form a circle $400 \mathrm{~mm}$ in diameter centred on the origin, and the other eight $\left(\mathrm{J}_{1}, \mathrm{~J}_{2}, \ldots, \mathrm{J}_{3}\right)$ form another circle $600 \mathrm{~mm}$ in diameter for section $\mathrm{A}$, and $700 \mathrm{~mm}$ for section D, centred on the same origin. The angle between adjacent pegs in each circle is $45^{\circ}$ (Fig. 3).

We can subdivide each array into several elements and determine the deformation ellipse for each element, on the two assumptions that the deformation in a particular element occurs in the principal plane and is homogeneous.

Three series of elements can be distinguished: one is

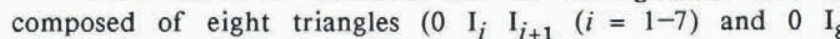
$\left.\mathrm{I}_{1}\right)$, another one of eight triangles $\left(0 \mathrm{~J}_{i} \mathrm{~J}_{i+1}(i=1-7)\right.$ and 
TABLE II. LOCATIONS OF OBSERVED ARRAYS, 1984

Tunnel section

\begin{tabular}{cccc}
\multicolumn{1}{c}{ Array } & $\mathbf{A}_{\mathbf{r}}$ & $\mathrm{A}_{\ell}$ \\
& to entrance & 9.9 & 9.9 \\
$\begin{array}{c}\text { Distance } \\
\text { (m) }\end{array}$ & to surface & 13.95 & 13.95 \\
& to floor & 0.55 & 0.53
\end{tabular}

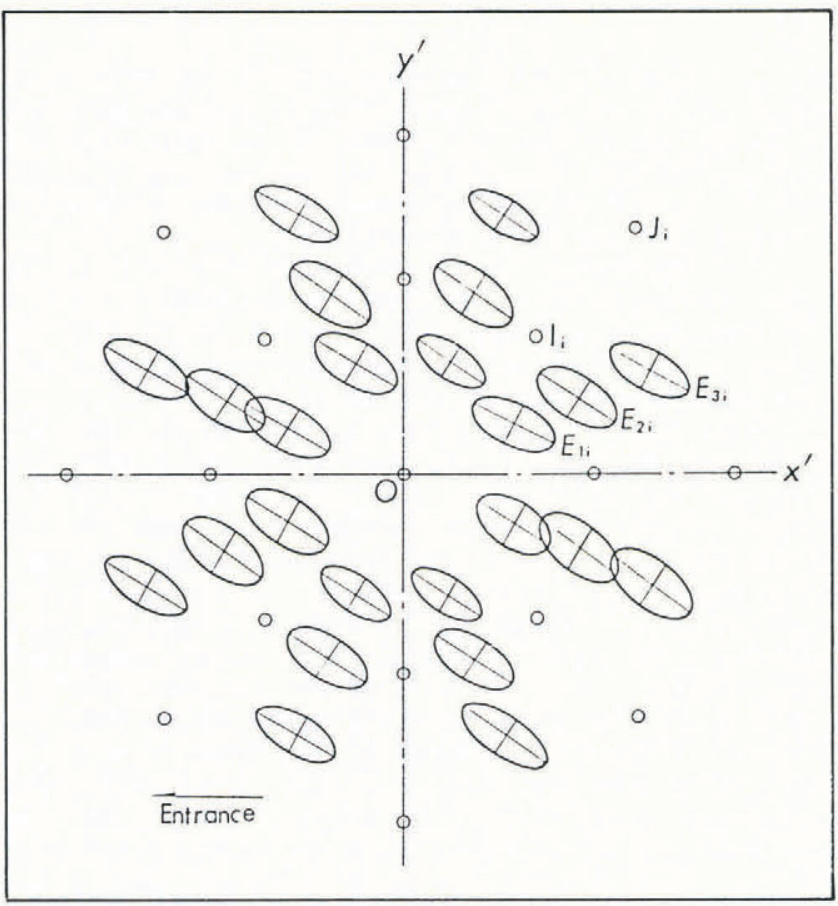

Fig. 3. Circular peg array for observing inhomogeneous deformation, together with three series of elements for calculating deformation ellipses.

$\begin{array}{lrrrr}\text { D-1 } & \text { D-2 } & \text { D-3 } & \text { D-4 } & \text { D-5 } \\ & & & & \\ 34.7 & 34.7 & 34.7 & 34.7 & 34.7 \\ 13.35 & 14.85 & 16.35 & 17.85 & 19.35 \\ 6.95 & 5.45 & 3.95 & 2.45 & 0.95\end{array}$

TABLE IV. AVERAGE VALUES OF MAJOR AXIS (a), MINOR AXIS (b), PRINCIPAL DIRECTIONS $\left(\alpha,{ }^{\circ}\right)$ AND ROTATION OF PRINCIPAL AXIS ( $\omega,{ }^{\circ} /$ year) FOR DEFORMATION ELLIPSES, 1983

\begin{tabular}{|c|c|c|c|c|c|c|c|c|c|}
\hline Array & $\begin{array}{c}\text { Distance to } \\
\text { entrance }\end{array}$ & & $\mathbf{a}$ & & 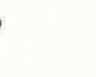 & $\alpha$ & & & $\omega$ \\
\hline A-1 & 10 & 1.44 & \pm 0.04 & 0.54 & \pm 0.04 & -21 & \pm & 4 & 26 \\
\hline$A-2$ & 10 & 1.54 & \pm 0.10 & 0.49 & \pm 0.05 & -21 & \pm & 5 & 31 \\
\hline B-1 & 17 & 1.19 & \pm 0.01 & 0.75 & \pm 0.02 & -35 & & 2 & 14 \\
\hline B-2 & 17 & 1.23 & \pm 0.01 & 0.71 & \pm 0.02 & -37 & \pm & 2 & 14 \\
\hline$C-1$ & 29 & 1.12 & \pm 0.00 & 0.82 & \pm 0.02 & -41 & & 5 & 8 \\
\hline C-1 & 29 & 1.10 & \pm 0.02 & 0.84 & \pm 0.03 & -47 & \pm & 4 & 7 \\
\hline D-1 & 42 & 1.02 & \pm 0.02 & 0.94 & \pm 0.03 & -57 & \pm & 16 & 2 \\
\hline D-2 & 42 & 1.04 & \pm 0.01 & 0.92 & \pm 0.01 & -62 & \pm & 5 & 1 \\
\hline D-3 & 42 & 1.03 & \pm 0.02 & 0.91 & \pm 0.01 & -56 & \pm & 6 & 2 \\
\hline D-4 & 42 & 1.05 & \pm 0.01 & 0.90 & \pm 0.02 & -55 & \pm & 5 & 4 \\
\hline D-5 & 42 & 1.05 & \pm 0.02 & 0.91 & \pm 0.01 & -57 & \pm & 4 & 1 \\
\hline D-6 & 42 & 1.06 & \pm 0.01 & 0.89 & \pm 0.01 & -55 & \pm & 1 & 0 \\
\hline E-1 & 55 & 1.06 & \pm 0.01 & 0.87 & \pm 0.02 & -58 & \pm & 2 & 2 \\
\hline E-2 & 55 & 1.07 & \pm 0.02 & 0.84 & \pm 0.02 & -58 & \pm & 4 & 1 \\
\hline F-1 & 65 & 1.02 & \pm 0.02 & 0.96 & \pm 0.01 & -54 & \pm & 7 & J \\
\hline F-2 & 65 & 1.03 & \pm 0.02 & 0.94 & \pm 0.02 & -50 & \pm & 3 & $?$ \\
\hline
\end{tabular}

Continuity

No shear faulting or fracturing was observed in the walls of the tunnel in 1983 or in 1984. All of the circular peg arrays deformed regularly to ellipses. Therefore, we believe that the bulk ice near the base of the glacier shows continuous deformation.

\section{Strain state}

The deformation of bulk ice, which was observed from 13 January to 24 November 1983 and processed in the same way as the analysis for inhomogeneity, is summarized in Table IV. Both arrays $\mathrm{A}-1$ and $\mathrm{A}-2$ are in section $\mathrm{A}$ but array $\mathrm{A}-1$ is above array $\mathrm{A}-2$, and so on. Huang and others (1987) have interpreted the general states of strain-rate and stress. Any plane deformation can be

TABLE III. AVERAGE VALUES AND STANDARD DEVIATIONS OF MAJOR AXES (a), MINOR AXES (b), AND PRINCIPAL DIRECTIONS $\left(\alpha^{\circ}\right)$, FOR DEFORMATION ELLIPSES, 1984

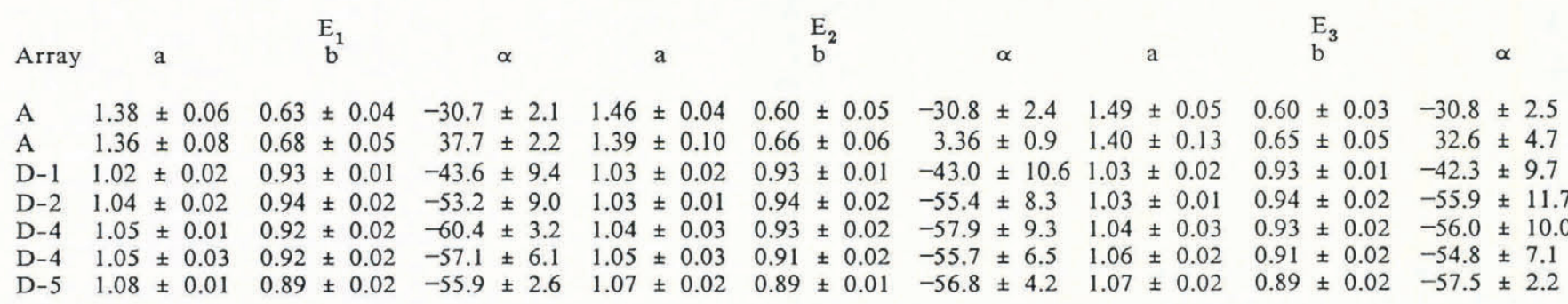


regarded as superimposed deformation due to pure shear and simple shear (Han, 1984). Pure deformation is linear deformation in the principal direction without rotation of the principal direction. Simple shear results in rotation of the principal direction. Therefore, rotation of the principal direction can be used as a measure of simple shear. From Table IV, we can see that rotation of the principal direction is infinitely small in the inner part of the tunnel and increases from the back wall towards the entrance of the tunnel. This is somewhat different from the model of Hooke and Hudleston (1978), who suggested that simple shear predominates near the base of a glacier. However, it is true that simple shear becomes progressively more important as the ice moves out towards its margins. The tunnel was excavated in an area of severe compressive deformation (Fig. 1). Severe compression may accompany a dominant pure shear. Nevertheless, in the ablation area of a glacier, the main flow state is one of compressive flow. We therefore have no doubt that what we have observed in the tunnel is typical of the ablation area in an extra-continental type glacier.

\section{SUMMARY}

Urumqi Glacier No. 1 is a small extra-continental type glacier. The zero isopleth of surface areal strain-rate is roughly parallel to, but below, the equilibrium line. In the ablation area, the ice temperature is quite low in the active layer but it increases rapidly with depth. In the middle and lower parts of the ablation area, the basal temperature is close to or at the melting point, whereas above and around the equilibrium line the glacier is frozen to its bed. Above the ice-laden subglacial till there is clear bulk ice, which is deforming continuously and inhomogeneously, but in the inner parts of the glacier, where the strain-rate is smaller, the inhomogeneous component of deformation is not significant, so that homogeneous deformation can only be assumed conditionally. However, this is no longer valid at the margins of the glacier, where the shear strain-rate is greater. In the ablation area, pure shear is predominant near the base of the glacier and simple shear becomes progressively more important as the ice moves out towards its margins.

\section{ACKNOWLEDGEMENTS}

The authors wish to thank Dr W.S.B. Paterson for his comments and for a critical review of this paper.

\section{REFERENCES}

Cai Baolin, Huang Maohuan, and Xie Zichu. 1987. A preliminary research on the temperature in deep boreholes of Glacier No. 1, Urumqi River headwaters. Kexue Tongbao, 32(22), 1732-1733. [In Chinese.]

Echelmeyer, K. 1987. Anomalous heat flow and temperatures associated with subglacial water flow. International Association of Hydrological Sciences Publication 170 (Symposium at Vancouver 1987 - The Physical Basis of Ice Sheet Modelling), 93-104.

Echelmeyer, K. and Wang Zhongxiang. 1987. Direct observations of basal sliding and deformation of basal drift at sub-freezing temperatures. J. Glaciol., 33(113), 83-98.

Han Yuying. 1984. Geometry of finite deformation and its application to geology. Beijing, Publishing House of Geology, 36-74. [In Chinese.]

Hooke, R.LeB. and P.J. Hudleston. 1978. Origin of foliation in glaciers. J. Glaciol., 20(83), 285-299.

Huang Maohuan and Wang Zhongxiang. 1987. Research on the tunnel excavated in Urumqi Glacier No. 1, Tianshan Glaciological Station, China. J. Glaciol., 33(113), 99-104.

Huang Maohuan, Wang Zhongxiang, and Ren Jiawen. 1982. On the temperature regime of continental-type glaciers in China. J. Glaciol., 28(98), 117-128.

Meier, M.F., W.B. Kamb, C.R. Allen, and R.P. Sharp. 1974. Flow of Blue Glacier, Olympic Mountains, Washington, U.S.A. J. Glaciol, 13(68), 187-212.

Ren Jiawen, Zhang Jinhua, and Huang Maohuan. 1985. A study of ice temperature in No. 1 Glacier in the Urumqi River headwaters, Tianshan. J. Glaciol. Geocryol., 7(2), 141-152. [In Chinese.]

Sun Zuozhe, Chen Yaowu, You Genxiang, and Han Jiankang. 1985. Flow characteristics of Glacier No. 1 at the headwater of Urumqi River, Tianshan. J. Glaciol. Geocryol., 7(1), 27-40. [In Chinese.]

Zhang Xiangsong, Zhu Guocai, Qian Songlin, Chen Jiyang, and Shen Ying. 1985. Radar measuring ice thickness of No. 1 Glacier at the source of Urumqi River, Tianshan. J. Glaciol. Geocryol., 7(2), 153-162. [In Chinese.] 